\title{
CONTRADIÇÕES NA ARTICULAÇÃO DOS ENTES FEDERADOS PARA IMPLEMENTAÇÃO DA POLÍTIÇA NACIONAL DE FORMAÇÃO DE PROFESSORES
}

\author{
CONTRADICCIONES EN LA INTERACCIÓN DE LAS ENTIDADES \\ FEDERADAS PARA LA APLICACIÓN DE LA POLÍTICA NACIONAL DE LA \\ FORMACIÓN DE PROFESORES
}
CONTRADICTIONS IN THE INTERACTION OF FEDERATED ENTITIES FOR IMPLEMENTATION OF NATIONAL TEACHER EDUCATION POLICY

\author{
Leila Pio MORORÓ ${ }^{1}$ \\ Rene SILVA ${ }^{2}$
}

RESUMO: Neste texto, a implementação do Plano Nacional de Formação de Professores - PARFOR é investigada a partir do regime de colaboração entre os entes federados, analisando os processos dialógicos e suas contradições no estado da Bahia. $\mathrm{O}$ caminho teórico-metodológico adotado foi o Materialismo Histórico Dialético, compreendido como um método que permite a apreensão da realidade em sua totalidade. A pesquisa indicou quatro principais questões, as quais, analisadas sob a perspectiva do contexto capitalista atual, se relevam como contradições na política de formação de professores atual.

PALAVRAS-CHAVE: Política de Formação de Professores. PARFOR. Regime de Colaboração.

RESUMEN: La aplicación del Plan Nacional de Formación Docente - parfor se investiga desde el régimen de colaboración entre las autoridades federales, el análisis de los procesos dialógicos y sus contradicciones en el estado de Bahía. El enfoque teórico y metodológico adoptado fue el materialismo histórico dialéctico, entendida como un método que permite la aprehensión de la realidad en su totalidad. La investigación indicó cuatro tipos de problemas que, analizado desde la perspectiva del contexto capitalista actual, son comprendidos como contradicciones en la política de formación docente actual.

PALAVRAS CLAVE: Política de Educación de profesor. PARFOR. Esquema de colaboración.

ABSTRACT: The implementation of the National Plan for Teacher Training - PARFOR is investigated from the regime of collaboration among federal entities, analyzing the dialogic processes and their contradictions in the state of Bahia. The theoretical and methodological approach adopted was the dialectical historical materialism,

\footnotetext{
1 Docente titular da Universidade Estadual do Sudoeste da Bahia vinculada ao Programa de PósGraduação em Educação. Email: lpmororo@yahoo.com.br

${ }^{2}$ Mestre em educação pelo PPGED da UESB, docente e coordenador pedagógico da rede municipal de educação de Itarana, Bahia, consultor MEC para a criação e implementação dos planos de cargos e salários do municípios. Email: renesilvaweb@ hotma.com
} 
understood as a method that allows the apprehension of reality in its totality. The research indicated four main issues which, analyzed from the perspective of the current capitalist context, fall within as contradictions in the current teacher training policy.

KEYWORDS: Teacher Education Policy. PARFOR. Collaboration Scheme.

\section{Introdução ou de como as contradições se estabelecem}

A pesquisa discutida neste artigo teve como objetivo investigar a implementação do Plano Nacional de Formação de Professores da Educação Básica (Parfor), um dos principais desdobramentos da Política Nacional de Formação de Professores, instituída no Brasil no ano de 2009. Diferentemente de pesquisas realizadas até então sobre os programas de formação em serviço de professores, esta teve como foco a dinâmica de articulação entre os diferentes sujeitos que representam os entes federados, a partir do que preconiza o Decreto Federal 6.755 (BRASIL, 2009a), o qual destaca que a Política Nacional de Formação de Professores deve ser efetivada em regime de colaboração entre União, Estados, Distrito Federal e Municípios.

É importante destacar que este estudo parte da compreensão das políticas públicas como "resultado da dinâmica do jogo de forças que se estabelecem no âmbito das relações de poder, relações essas constituídas pelos grupos econômicos e políticos" (BONETI, 2007, p.74). A política de formação de professores, portanto, como um dos âmbitos das políticas públicas educacionais, não é estática, mas dinâmica, sofrendo constante transformação, sendo influenciada e influenciando os embates que vão se constituindo entre esses grupos. Para compreendê-la no cenário atual, faz-se necessário entender o projeto político do Estado a partir de um contexto global, e as contradições do momento histórico em questão, cujas características principais aqui discutidas estão atreladas à crise do capitalismo internacional (o qual vem proporcionando transformações aceleradas nos aspectos econômico, político e social) e às políticas públicas que se configuram sob o campo de regulação do capital exercido pelos seus organismos. Nesse contexto, a atual política de formação de professores ocupa posição relacional, estrutural, histórica, dinâmica e contraditória dentro da totalidade da reprodução social (MASCARO, 2013).

Como um programa originado no interior de uma política que insere a formação de professores como um dos eixos estratégicos para a consolidação de reformas 
educacionais, o Parfor foi sinalizado pelo Decreto Presidencial 9.094 em 2007 (BRASIL, 2007), o qual, através do inciso XII, estabeleceu como uma de suas diretrizes “instituir programa próprio ou em regime de colaboração para formação inicial e continuada de professores da educação". Foi instituído oficialmente através da Portaria Normativa n$^{\circ}$ 09/2009, publicada em 30 de junho de 2009, uma ação conjunta do MEC, por intermédio da Capes, em colaboração com as Secretarias de Educação dos Estados, Distrito Federal e Municípios e as Instituições Públicas de Educação Superior. Segundo essa Portaria, as ações do Plano seriam definidas em "acordos de cooperação técnica" específicos, celebrados pela Capes e as Secretarias de Educação dos estados, objetivando a mútua cooperação técnico-operacional para organizar e promover a formação de professores das redes públicas de educação básica. Da mesma forma, as Instituições Públicas de Educação Superior (IPES) deveriam formalizar sua participação por intermédio de Termo de Adesão aos respectivos Acordos de Cooperação.

A Portaria Normativa n ${ }^{\circ}$ 09/2009, ao instituir o Parfor, criou também o sistema eletrônico denominado "Plataforma Paulo Freire", que gerencia "a participação nos cursos de formação inicial e continuada voltados para os profissionais do magistério das redes públicas da educação básica no âmbito do Plano Nacional de Formação de Professores" (BRASIL, 2009b). Os professores interessados devem efetuar sua préinscrição por meio da "Plataforma Paulo Freire" e as secretarias de educação dos municípios deveriam analisar as pré-inscrições efetuadas, validando aquelas que correspondem às necessidades da respectiva rede. Para realizar a validação, as secretarias de educação dos municípios tiveram que aceitar o Termo de Adesão ao Parfor, no qual já constavam definidas as responsabilidades e atribuições dos municípios.

Além do arcabouço normativo acima, o qual deu sustentação à constituição e operacionalização do Plano, a Capes disponibilizou no seu sítio eletrônico ${ }^{3}$ o "Manual Operativo do Parfor Presencial", que descreve todos os procedimentos necessários para efetivação do regime de colaboração na implementação do Parfor. Nesse, apesar do Decreto 6.755 (BRASIL, 2009a), no inciso III do art. 5, deixar definido que as “atribuições e responsabilidades de cada partícipe, com especificação dos compromissos assumidos, inclusive financeiros" precisariam ser definidas e contempladas no plano estratégico a ser formulado pelos Fóruns Estaduais Permanentes de Apoio à Formação

${ }^{3}$ Manual Operativo do Parfor <http://www.capes.gov.br/educacao-basica/Parfor> acesso em 23 de maio de 2014. 
Docente, no Manual foram definidas as atribuições de todos os envolvidos no processo (Capes, Estados, Municípios, Fóruns Estaduais, IES).

Para a realização da pesquisa aqui apresentada, foi tomado como unidade de análise o Território de Identidade do Vale do Jiquiriçá ${ }^{4}$, levando em consideração que a articulação promovida pelos sujeitos que atuaram no período de 2009 a 2012 frente as secretarias municipais de educação dos municípios desse território, através do Educavale $^{5}$, provocaram coletivamente a construção de debates a respeito da formação de professores e de organização do Parfor, situação até então inédita no estado da Bahia. Como consequência desse movimento, houve uma reestruturação por parte do Fórum Estadual Permanente de apoio à Formação docente da Bahia (Forprof/Ba), outro importante desdobramento da Política Nacional de Formação de professores, e das Instituições Públicas do Ensino Superior envolvidas para e no atendimento da demanda de formação de professores dos municípios desse território.

O quadro de demanda ${ }^{6}$ construído em 2011 pelo Educavale indicava que 1.390 professores das redes de educação de 21 municípios do Vale do Jiquiriçá estavam atuando em sala de aula de escolas de educação infantil e ensino fundamental sem a formação em nível superior. Destes, 932 eram professores que atuavam especificamente na educação infantil e séries iniciais do ensino fundamental, necessitando, portanto, da formação em Pedagogia. Até o início do ano de 2014, apenas sete municípios estavam sendo atendidos pelo Parfor através da constituição de cinco Polos de Formação de Professores ${ }^{7}$.

As dificuldades quanto ao processo de planejamento, organização e execução do plano, agravadas pela ausência de análises seguras e do diálogo mais organizado e substanciado entre os sujeitos envolvidos no Forprof-Ba, fomentou a necessidade de investigar as responsabilidades de cada ente federado. Desta forma, além de ouvir os

${ }^{4}$ O Território do Vale do Jiquiriçá está localizado a $150 \mathrm{~km}$ a oeste de Salvador e possui 21 municípios distribuídos por uma área total de 12.415,98 $\mathrm{km}^{2}$ (Fonte: SEPLAN-SEI < http://www.sigbahia.ba.gov.br/Cardapio/sigRelTerritorios>).

${ }^{5}$ No território, no ano de 2009, foi criada formalmente a Associação dos Municípios do Vale do Jiquiriçá (Mercovale), uma iniciativa dos prefeitos com o objetivo de ampliar e fortalecer a capacidade administrativa, econômica e social dos municípios. No estatuto da entidade, também previa estimular e auxiliar a organização de Fóruns de Secretários Municipais - Educavale, visando ações integradas.

${ }^{6}$ Levantamento realizado pelo EDUCAVALE, no qual cada município do território informa a quantidade de professores que atuam na educação básica em suas redes de ensino que ainda não possuem a formação inicial em nível superior.

${ }^{7}$ Nomenclatura utilizada para o estabelecimento de oferta de cursos de forma regionalizada dentro do Território do Vale do Jiquiriçá. Um Polo corresponde a um curso oferecido por uma Instituição de Ensino Superior em determinado município, levando em consideração a demanda de formação e a proximidade entre os municípios atendidos. Este conceito foi elaborado nas discussões do EDUCAVALE com IAT e o Forprof. 
representantes dos entes federados (União, Estado e Municípios) que estiveram à frente do processo de implantação do Parfor no período de 2009 a 2012, também foi realizada a análise de documentos legais, normativos e de registro de reuniões dos fóruns envolvidos (Educavale e Forprof-Ba).

Foram entrevistados os secretários municipais de educação, os diretores do Instituto Anísio Teixeira (IAT), instância responsável em coordenar os trabalhos do Fórum Estadual Permanente de Formação Docente (Forprof-Ba) no estado da Bahia e o ex-coordenador e coordenador atual da Coordenação Geral de Docentes da Educação Básica da Coordenação de Aperfeiçoamento de Pessoal de Nível Superior (Capes) que assumiram o cargo no período correspondente à pesquisa.

A direção epistemológica definida para a pesquisa teve como base teórica e metodológica o Materialismo Histórico Dialético, uma vez que, acredita-se, essa fornece os fundamentos para um estudo da realidade em seu movimento, indo além da aparência fenomênica, analisando as partes em constante relação com a totalidade, procurando perceber as contradições inerentes a esse processo, que é dinâmico (LUKÁCS, 2012; MORORÓ, 2005).

A pesquisa evidenciou que o processo de implementação do Parfor foi extremamente conflituoso, consequência de um movimento verticalizado da Política Pública que chega, inclusive, a ferir as próprias normas que a regulamenta. A análise desse processo expôs algumas das contradições na articulação entre os entes federados envolvidos na implementação do Parfor no Vale do Jequiriçá, as quais serão discutidas neste texto. São elas: o Fórum como importante elemento de materialização do regime de colaboração; o diálogo entre municípios e IES como alternativa efetiva de adequação de demanda de formação e oferta de cursos; os Polos de Formação regionalizados como caminho para implementação do Parfor; e o apoio financeiro aos municípios como condição essencial da implementação do Parfor.

\section{O Fórum Estadual Permanente de Apoio à Formação Docente como importante espaço de materialização do regime de colaboração}

A primeira questão empírica que ajuda a desvelar a contradição no movimento dialético de implementação do Parfor diz respeito à negação dos Fóruns Estaduais Permanentes de Apoio à Formação Docente como espaço de cumprimento dos objetivos 
da Política Nacional de Formação de Professores em regime de colaboração entre os entes federados.

Apesar de terem sido instituídos em 2009 (e reestruturados em 2016 pelo Decreto 8.752), a pouca literatura existente a esse respeito e os dados analisados na pesquisa desenvolvida demostraram que os Fóruns demoraram muito para serem constituídos. Entre a aprovação do Decreto 6.755/2009, que instituiu a Política Nacional de Formação dos Profissionais do Magistério da Educação Básica e cria os Fóruns, e a normatização de funcionamento dos mesmos, em 16 de setembro de 2009, a partir da publicação da Portaria $n^{\circ}$ 883, transcorreram-se sete meses. O Parfor, portanto, foi lançado e começou a funcionar sem a existência dos Fóruns, os quais, por suas atribuições, dentre outras, deveriam, desde o início do processo de implementação do Parfor, dar amplo conhecimento aos sistemas de ensino sobre as diretrizes e prioridades da Política de Formação, subsidiar os sistemas de ensino na definição de diretrizes pedagógicas e estabelecer os critérios para a definição de prioridades para a participação dos professores nos cursos, elaborar e acompanhar a execução do plano estratégico.

É importante destacar o quanto essa morosidade na definição das atribuições dos Fóruns contribuiu para os problemas enfrentados no processo de implantação do Parfor.

Com o Parfor em andamento, depois de um intenso processo de divulgação nacional em comerciais de TV convidando os professores a se inscreverem na "Plataforma Freire", os municípios, que sequer ainda tinham tido a oportunidade de compreender a dinâmica do programa, ficaram, em um primeiro momento, à margem do processo, passando a enfrentar grandes desafios.

A falta de informação tanto por parte dos municípios quanto dos professores provocou muitos equívocos, inclusive com inscrições de pessoas não docentes na "Plataforma Freire" e a validação pela própria Capes de todas essas inscrições, como aponta a ex-direção do IAT:

O que aconteceu quando o Parfor foi implementado? [...] se você oferta agora, não tinha garantia que teria uma outra oferta no futuro. Isso fez com que todo mundo viesse solicitar, demandar serviço, porque isso é a chance de ter a sua formação garantida. [...] por outro lado, os professores, no desespero de entrar na Plataforma, se não tivesse aquele curso naquela região, eles entravam em qualquer curso que tivesse. Essas questões foram questões que depois colocaram em risco o próprio programa. Houve de forma muito intempestivamente, sem planejamento. (IAT2) 
A precipitação por parte da Capes em iniciar o programa sem a necessária compreensão por parte de todos os envolvidos de seu funcionamento, aliada à tardia normatização das atribuições dos Fóruns, adiou também a elaboração do plano estratégico de formação para o estado da Bahia. Este documento deveria conter diagnóstico e identificação das necessidades de formação, bem como a capacidade de atendimento das instituições superiores envolvidas; deveria definir as ações a serem desenvolvidas para o atendimento das necessidades de formação e as atribuições e responsabilidades de cada partícipe com especificação dos compromissos assumidos, inclusive financeiros, em relação à formação inicial e continuada.

Em relação ao Parfor baiano, como o programa já estava em andamento quando essas atribuições foram definidas, as responsabilidades dos entes federados e das instituições de ensino superior foram estabelecidas através de acordos de cooperação entre Capes/Estados, Estados/IPES e através da assinatura de um Termo de Aceite assumido pelos municípios na própria Plataforma. Portanto, cabe refletir qual seria o papel do plano estratégico nesse contexto? Validar o que já tinha sido iniciado? Uma nova prática de gestão coletiva da formação de professores na Bahia teria força suficiente para superar velhas práticas verticalizadas de gestão de políticas públicas?

A saída encontrada pela Capes para suprir a ausência dos planos estratégicos foi a publicação do Manual Operativo do Parfor Presencial em 2013. Em que pesem as críticas a esse respeito, essa medida reduziu o número de equívocos na condução do Plano. O que acabou por revelar que a Capes, como articuladora nacional, representante da União no regime de colaboração desejado, tardou em assumir o papel inicial de coordenação, regulação e planejamento no que se refere à implantação do novo modelo de gestão que a Política Nacional e o Parfor exigiam.

O Forprof-Ba não se constituiu como espaço de materialização do regime de colaboração, tal como esperado. Isto é, como um espaço no qual se passe verdadeiramente a coordenar a construção e consolidação de uma política de formação, a qual, ao congregar as diferentes representações dos entes federados, das instituições de ensino superior (IES), de entidades representativas, sindicados de professores, considere as condições territoriais e locais e as especificidades das demandas apresentadas.

Fazia-se necessário também o estabelecimento de acordos entre aqueles que detêm a demanda e os que detêm a oferta, isto é, as redes públicas de ensino e as IES. Entretanto, no estado da Bahia, o estabelecimento desse acordo logo se tornou um problema a mais. A falta de diálogo entre os municípios e as IES para adequação entre 
demanda de formação e oferta de cursos teve como consequência diversos problemas na implementação do Parfor, o que se apresenta como uma segunda contradição dentro desse processo.

Mesmo sem a intermediação dos Fóruns a partir dos planos estratégicos, o próprio Manual Operativo do Parfor apontava que municípios e IES deveriam se articular para compatibilização dos calendários escolares de sua rede com os cursos de formação, de modo que não ocorressem prejuízos quanto a participação e permanência dos professores nos cursos.

Entretanto, não foi o que aconteceu inicialmente na implementação do Parfor no estado da Bahia. As IES formataram sua oferta de curso tendo como base o modelo dos cursos que já eram oferecidos.

No Vale do Jiquiriçá houve um movimento inverso. Os municípios, valendo-se da prerrogativa do regime de colaboração (mesmo que ainda sem a plena consciência dela), iniciaram uma articulação para discutir com os demais partícipes representantes dos entes federados e das IES as formas de atendimento da demanda de formação inicial de professores dos municípios daquele território.

A iniciativa dos municípios horizontalizou as discussões em torno do processo de implementação do Parfor, ao assumir esses uma postura protagonista, apresentando e organizando suas demandas.

Foram os municípios do Vale do Jiquiriçá que sugeriram que, ao invés levar seus 932 professores para os campi das IES, fossem criados polos de formação de professores mais regionalizados que reunissem um número de municípios pela proximidade geográfica, diminuindo assim a distância a ser percorrida pelos professores e, consequentemente, os gastos com esse deslocamento.

Sem dúvidas, o diálogo direto com as IES se mostrou eficiente dentro desse contexto inicial de implantação do Parfor, sendo, inclusive, reconhecido pelo Forprof/BA, a partir de sua coordenação, e também pela Capes como uma alternativa a ser generalizada para todo o estado.

A proposta de criação de Polos de Formação regionalizados dentro do movimento de implementação do Parfor constituiu-se em uma negação do formato de oferta de cursos propostos até então pelas IES baianas, se revelando, assim, como uma terceira contradição no processo de estabelecimento do regime de colaboração entre os entes federados. 
No Vale do Jiquiriçá a discussão em torno da formação de professores centrou-se na demanda pelo curso de Pedagogia, e a alternativa apresentada, como exposto anteriormente, foi a criação dos Polos de Formação.

O relato dos dirigentes municipais de educação aponta que a criação desses polos resultou na superação de muitos problemas gerados pelo formato inicial de oferta de cursos. Superação não apenas de problemas de ordem de garantia de condições para que os professores frequentassem os cursos, mas superação de problemas pedagógicos, de deslocamento de professores do campo e funcionamento das escolas.

Nós queremos aqui colocar um ponto extremamente importante, a questão do professor da zona rural. Nós temos trinta e duas escolas do campo, e essas escolas ficam muitas vezes em lugares muito distantes, [...] esses professores, tiveram a oportunidade de cursar uma graduação aqui, o que favoreceu muito [...]. Com esse formato não causou transtorno a rede escolar. Então, foi de grande valia para Maracás e acredito também para Planaltino. (Maracás)

Dada as especificidades territoriais do Estado da Bahia, é preciso efetivamente fomentar esses diálogos territoriais e locais como extensão da prática do regime de colaboração, empoderando esses espaços como legítimos na definição da melhor forma de atendimento da demanda de formação de professores, seja através de Polos de Formação mais regionalizados ou outras formas que podem surgir deste diálogo. O lócus de formação é, sem dúvida, a universidade, mas essa precisa estar presente onde houver a necessidade.

Um elemento que, no movimento de estabelecimento do regime de colaboração durante a implementação do Parfor, esteve presente a todo momento, e a sua negação pode vir a impedir a possibilidade real de efetivação da Política de Formação Inicial, diz respeito ao apoio financeiro aos municípios.

No início do processo de implementação do Parfor, a dificuldade em garantir as contrapartidas de deslocamento, hospedagem, alimentação e contratação de professor substituto estava diretamente ligada aos recursos financeiros. Esta questão ficou bem clara nos depoimentos dos representantes municipais.

Tivemos dificuldades financeiras com relação ao translado desses profissionais [professores da Educação Básica]. Também dizia lá [no termo de aceite da Plataforma Paulo Freire] que tinha que pagar hospedagem, alimentação e transporte. Então os professores exigiam, queriam que nós pagássemos e nós tínhamos dificuldades financeiras porque tínhamos que manter profissional substituto e manter a 
logística desse professor na universidade [...]. A problemática era quase comum: a questão financeira dos municípios de garantir e assegurar o translado, o deslocamento desse profissional. Como os municípios iriam custear isso? (Jaguaquara)

A questão financeira aparece como crucial. Alguns municípios não avançaram na criação dos polos de formação justamente por conta da dificuldade em alocar recursos do orçamento municipal para garantir as contrapartidas que eram impostas para a adesão.

A gente entendia a importância, sabíamos que aqui seria fundamental para o município, sabia também dos limites financeiro do próprio município, mas entendia que, sobretudo os prefeitos, precisavam dialogar para acertar tudo isso, e a gente não conseguiu fazer com que esses prefeitos entendessem que aquilo era uma prioridade a ponto deles sentarem, definirem na prática, como iriam operacionalizar, executar de fato essa proposta de implantação do polo do Parfor em Brejões. (Brejões)

Para além do interesse ou não dos prefeitos, a questão financeira realmente aparece como um elemento que tem um peso importante nas dificuldades de concretização dos Polos de Formação. Mesmo os municípios que conseguiram implantar o Polo apresentaram dificuldades nesse sentido.

Na própria elaboração da Política Nacional de Formação dos Profissionais do Magistério da Educação Básica as contrapartidas e responsabilidades dos entes federados não ficaram claras, tal como aponta um dos ex-diretores da Educação Básica da Capes.

Não foi pensada, ou melhor, não conseguimos consensos internamente para levar à frente o regime de colaboração e a construção do sistema nacional de formação de professores, um anseio antigo dos educadores que necessita ser materializado [...] não havia uma política de apoio, nem mesmo a determinação, indução, regulação, como queiramos denominar, que mobilizasse os municípios a apoiar seus professores em formação. Tampouco o Ministério tomava a iniciativa nesse sentido, apesar das demandas constantes para que o próprio MEC oferecesse a bolsa formação. Sabemos das dificuldades dos municípios na liberação de seus professores, pois não há substitutos disponíveis que assumam as classes. O Plano Estratégico da Formação, construído pelo Fórum Estadual Permanente de Apoio À Formação Docente em cada estado, não contemplava essa situação, até porque não há mesmo alternativas para uma situação de formação no exercício do trabalho. (Capes1)

Justamente pelo programa ser viabilizado em regime de colaboração é que se faz necessário discutir as responsabilidades legais de cada ente federado.

O texto do Decreto 6.755, em seu artigo $9^{\circ}$, deixa claro a possibilidade de apoio financeiro não apenas às IES, como vem ocorrendo, mas também aos Estados, Distrito 
Federal e Municípios, o que não vem ocorrendo. Com isso, em particular os municípios, estão tendo que arcar com uma despesa que, do ponto de vista legal, no mínimo não poderia ser deles, uma vez que o art. 11 da LDB deixa bem claro que a responsabilidade dos municípios deve ser com a educação infantil e o ensino fundamental, permitindo a aplicação de recursos em outros níveis de ensino somente se essas etapas estiverem completamente atendidas, com percentuais de aplicação de recursos acima do mínimo vinculado pela Constituição.

Cabe aqui esclarecer que, mesmo sendo o Parfor um programa de formação em serviço de professores da educação básica, não se pode admitir que recursos da educação básica sejam destinados para a formação desses professores, uma vez que a própria LDB, no seu art. 62, deixa claro que "a formação de docentes para atuar na educação básica far-se-á em nível superior, em curso de licenciatura, de graduação plena em universidades e institutos superiores de educação" (BRASIL, 1996a). Se a formação é em nível superior, se, por um lado, na própria LDB não fica claro de quem é a responsabilidade, por outro lado fica claro que ela não é dos municípios.

Como afirma Saviani (2010, p. 386-387),

\begin{abstract}
A formação de professores, a definição da carreira e as condições de exercício docente constituem algo que dificilmente pode ser confiado aos municípios. Com efeito, a própria LDB, pelo inciso $\mathrm{V}$ do artigo 11 , impede-os de atuar na formação de professores, uma vez que poderão se dedicar a outros níveis de ensino ulteriores ao fundamental [...]. Dado que a formação de professores ocorre, como regra, no nível superior e, transitoriamente, no nível médio, escapa aos municípios essa atribuição. Segue-se que as questões relativas ao magistério constituem matéria de responsabilidade compartilhada entre União e Estados. (SAVIANI, 2010, p. 386 - 387)
\end{abstract}

Os Polos de Formação regionalizados parecem se constituir em uma boa opção de atendimento da demanda de formação de professores, mas o sentimento demonstrado por um dos representantes municipais abaixo, exemplifica as necessidade de que é preciso repensar a questão financeira.

A proposta é boa [...] agora, eu vejo que vão continuar as mesmas dificuldades se for para ser viabilizado pelo município, acho que a contrapartida do município acaba ficando alta [...] então não é coisa tão simples assim, eu acho que nesse modelo as dificuldades vão continuar existindo, se tiver que contar com a contrapartida grande do município. (Brejões) 
A responsabilidade de arcar com a formação inicial de professores não pode recair financeiramente apenas sobre os municípios. Faz-se necessário, então, que o Ministério da Educação encontre formas de garantir o apoio financeiro necessário aos municípios que precisarem aderir os planos e/ou programas de formação em nível superior de seus docentes.

Ainda a respeito do financiamento, a análise dos dados revelou que, no Manual Operativo do Parfor Presencial, o item 9 trata especificamente do apoio financeiro para as IES. A concessão de apoio financeiro é feita através de recursos de custeio e capital mediante aprovação de Plano de Trabalho encaminhado junto com Termo de Cooperação ou de Convênio.

Os recursos de custeio podem ser utilizados, entre outras coisas, para: a) compra de material de consumo - despesas relativas à aquisição de material para uso na implantação e desenvolvimento dos cursos; b) diárias nacionais e auxílio deslocamento destinadas a viabilizar a participação dos coordenadores, professores e alunos e palestrantes em atividades acadêmicas e pedagógicas; c) passagens aéreas nacionais, terrestres ou fluviais nacionais destinadas a viabilizar a participação dos coordenadores, professores, alunos e palestrantes em atividades acadêmicas e de campo; d) auxílio financeiro a estudantes.

Quanto aos recursos de capital, estes devem ser utilizados para aquisição de equipamentos e materiais permanentes, sendo: a) coleções e outros materiais bibliográficos para uso nas bibliotecas da instituição participante; b) material permanente e equipamentos para uso didático-pedagógico nas turmas implantadas no âmbito do Parfor Presencial.

É possível observar, portanto, que os recursos destinados às IES, pelo menos os recursos de custeio, poderiam tranquilamente ser utilizados para compra de materiais para implantação e desenvolvimento dos cursos no polo e pagamentos de gastos com atividades acadêmicas e pedagógicas, incluindo aulas de campo. No mesmo sentindo, os recursos de capital poderiam ser usados para compra de equipamentos e materiais permanentes para equipar os polos, inclusive com a montagem de biblioteca.

O cálculo para repasse destes recursos é feito tendo como base o número de turmas implantadas e previstas em cada IES. Em valores de 2014, por semestre, para cada turma implantada na sede, ou distante dela até $300 \mathrm{~km}$, era repassado o valor de R\$ 15.000,00 (quinze mil reais) de custeio, e para cada turma implantada em localidades 
com distância superior a $300 \mathrm{~km}$ da sede o valor repassado de custeio era de $\mathrm{R} \$$ 20.000,00 (vinte mil reais).

O valor de repasse de recursos de capital corresponde ao percentual de $30 \%$ do total de custeio, no entanto, esse repasse só ocorria quando houvesse disponibilidade de recursos na dotação orçamentária da Capes para esse fim. Numa turma ofertada fora de sede da IES, com distância de mais de $300 \mathrm{~km}$, esse valor representava, além dos R\$ $20.000,00$ (vinte mil reais) para custeio, $\mathrm{R} \$ 6.000,00$ (seis mil reais) a mais para capital, isso por semestre, o que daria um total de $\mathrm{R} \$ 52.000,00$ (cinquenta e dois mil reais)/ano por cada turma, o que daria para custear o deslocamento e o pagamento de diárias dos docentes do ensino superior.

Fica evidente, portanto, que é preciso aprofundar o debate sobre as responsabilidades financeiras do Parfor. Está demonstrado que há equívocos quanto a responsabilização dos municípios no financiamento da formação inicial, e talvez também haja na utilização dos poucos recursos disponíveis que são destinados às IES.

\section{Considerações finais ou das contradições às possibilidades de efetivação de uma política de formação inicial para os profissionais do magistério}

A pesquisa indicou que existem muitas questões a serem enfrentadas no processo de implementação do regime de colaboração entre os entes federados e a participação das IES na implementação da política nacional de formação de professores. Essas questões, em geral, desvelam contradições que, na materialização do Parfor, mesmo em outro momento histórico, expressam uma lógica na relação entre os entes federados com a responsabilização excessiva dos municípios e, consequentemente, dos professores, e uma desresponsabilização gradativa da União e dos estados.

Não há dúvidas de que o Decreto 6.755/2009 representou um avanço na Política de Formação de Professores. Não apenas porque, pela primeira vez no país, estabelece a formação de professores como um dever do Estado, mas também pelo fato de criar Fóruns Permanentes de apoio à formação como espaços de vivência do regime de colaboração entre os diversos entes federados para organização dos objetivos dessa política. Mas é preciso reconhecer que justamente a negação desse espaço como instância mobilizadora, articuladora e propositiva, trouxe, e ainda traz, inúmeros equívocos na implementação do Parfor. A partir do momento em que a Capes toma para si o papel de definidora dos procedimentos de operacionalização e responsabilidades 
com a publicação do Manual Operativo do Parfor Presencial, há uma negação do princípio colaborativo do programa, que mais do que um princípio do programa, representa uma grande conquista, fruto da luta histórica dos educadores. É preciso reconhecer que esse equívoco transformou os Fóruns em meros braços estatais da Capes para operacionalização do Parfor.

Os resultados da pesquisa evidenciam ainda que o fortalecimento dos Fóruns, horizontalizando cada vez mais as suas ações e discussões sobre a efetivação da Política de Formação de Professores, em específico do Parfor, ampliando mais ainda a participação dos entes federados através do diálogo territorial, local, consorciado ou não, com participação das IES para adequação entre demanda e oferta, discutindo a melhor forma de formatação dos cursos, sendo importante envolver inclusive representação dos professores, sem dúvidas contribuirá para um início de constituição de uma formação inicial dentro de uma perspectiva transformadora.

Apesar da pesquisa ter como finalidade compreender a Política de Formação a partir do regime de colaboração, existem outros fatores, como por exemplo, o currículo, a proposta pedagógica, a práxis educativa, que devem ser levados em conta na discussão de uma formação com bases sólidas voltada para a formação emancipatória.

Contudo, o que fica mais evidente a partir dos resultados da pesquisa é o fato de que não há possibilidades de efetivação de uma Política de Formação Inicial de Professores em Serviço se não se discutir com seriedade o apoio financeiro aos municípios. Não se pode continuar delegando aos municípios a responsabilidade de garantias de contrapartidas financeiras para o funcionamento do Parfor, sob o pretexto de que é formação para professores da educação básica, uma vez que esta formação ocorre em nível superior. A União precisa assumir sua responsabilidade de apoio financeiro aos municípios nesse processo, e temos que refutar veemente todas as tentativas de transferência dessa responsabilidade aos municípios e, quase sempre na impossibilidade desses, aos próprios professores.

E mais ainda, é preciso alertar que, mesmo os municípios não tendo o apoio financeiro, os recursos recebidos pela IES, a título de recursos de custeio e capital com base nas turmas do Parfor, precisam ser mais bem discutidos e estudados, uma vez que muitas das responsabilidades que estão sendo transferidas pelas IES aos municípios, sobretudo na implantação de Polos de Formação de Professores fora de sede, poderiam ser compartilhadas, ou na maioria dos casos, assumidas completamente pelas IES. 


\section{Referências}

BONETI, Lindomar Wessler. Políticas Públicas por dentro. $2^{\text {a }}$ Edição. Editora Unijuí: Ijuí, 2007.

BRASIL. Lei $n^{0}$ 9.394, de 20 de dezembro de 1996. Estabelece as Diretrizes e Bases da Educação Nacional. Brasília, DF, 20 dez. 1996. Disponível em: <http://www.planalto.gov.br/ccivil_03/leis/19394.htm>. Acesso em 24 de mai. 2014.

Decreto $\mathbf{n}^{0}$ 6.094, de 24 de abril de 2007. Dispõe sobre a Implementação do Plano de Metas Compromisso Todos pela Educação. Brasília, DF, 24 abr. 2007. Disponível em: <http://www.planalto.gov.br/ccivil_03/_ato20072010/2007/decreto/d6094.htm>. Acesso em: 24 de mai. 2014.

Decreto 6.755, de 19 de janeiro de 2009. Institui a Política Nacional de Formação dos Profissionais do Magistério e regulamenta a ação da Capes. Brasília, DF, 19 de jan. 2009a. disponível em: <http://www.planalto.gov.br/ccivil_03/_ato20072010/2009/decreto/d6755.htm>. Acesso em: 24 de mai. 2014.

Portaria Normativa $\mathbf{n}^{\circ}$ 9, de 30 de junho de 2009. Institui o Plano Nacional de Formação dos Professores da Educação Básica no âmbito do Ministério da Educação. Brasília, DF, 30 de jun. 2009b. Disponível em: < portal.mec.gov.br/dmdocuments/port_normt_09_300609.pdf >. Acesso em: 24 de mai. 2014.

Portaria $\mathbf{n}^{\mathbf{0}}$ 883, de 16 de setembro de 2009. Estabelece as diretrizes nacionais para o funcionamento dos Fóruns Estaduais Permanentes de Apoio à Formação Docente. Brasília, DF, 16 de set. 2009c. Disponível em: <portal.mec.gov.br/dmdocuments/port883.pdf>. Acesso em 24 de mai. 2014.

CAPES. Parfor Presencial - Manual Operacional. Brasília, DF, 25 de fev. 2014. Disponível em: <http://www.Capes.gov.br/educacao-basica/Parfor>. Acesso em: 24 de mai. 2014.

EDUCAVALE. Regimento Interno do Fórum dos Secretários de Educação dos Municípios do Vale do Jiquiriçá. Jaguaquara, 14 de jun. de 2010.

FREITAS, Helena Costa Lopes de. Formação de professores no Brasil: 10 anos de embate entre projetos de formação. Educação e Sociedade, vol.23, no.80, p.136-167, Set 2002.

LUKÁCS, Györge. História e consciência de classe: estudos sobre a dialética marxista. $2^{\mathrm{a}}$ Ed. - São Paulo: Fontes, 2012.

MASCARO, Alysson Leandro. Estado e forma política. São Paulo, SP: Boitempo, 2013.

MORORÓ, Leila Pio. A política Nacional de Formação de Professores e o papel das universidades públicas. In: ALMEIDA, José R. M.; MAGALHÃES, Lívia D. R.; 
BERTONI, Luci Mara. As redes científicas e o desenvolvimento da pesquisa. Pedro e João editores: São Carlos, SP, 2011.

SAVIANI, Dermeval. Sistema Nacional de Educação Articulado ao Plano Nacional de Educação. Revista Brasileira de Educação. v.15, n.44, p. 380-412, maio/ago. 2010.

\section{Como citar este artigo:}

MORORÓ, Leila Pio.; SILVA, Rene. Contradições na articulação dos entes federados para implementação da política nacional de formação de professores. Revista IberoAmericana de Estudos em Educação, Araraquara, v.12, n.1, p. 440-455, 2017. Disponível em: <http://dx.doi.org/10.21723/riaee.v12.n1.8999>. E-ISSN: 1982-5587.

Data de submissão: out/2016

Aprovação final: fev/2017 